\title{
On the Idea of Organization Transformation: The IS/IT Design Challenge in Systems Thinking
}

\author{
Kam Hou Vat \\ University of Macau, Macau
}

fstkhv@umac.mo

\begin{abstract}
This paper investigates the idea of organization transformation appropriate to the advent of information technologies (IT). Specifically, we describe a traceable framework of transformation, which accommodates the shift of information system (IS) support from automating to informating to knowledging. The paper intends to clarify the context of IT/IS-based organization transformation through the contextualization of IS support and its relation to organizational design. This is done by elaborating the design issue of IS support that help structure and facilitate knowledge interconnectivity, through the exposition of the social processes in which, in a specific organizational context, a particular group of people can conceptualize their world and hence the purposeful action they wish to undertake. That provides the basis for ascertaining what information support is needed by those who undertake that action. Only then does it become appropriate to ask how modern IT can help to provide that support. We conclude by reiterating the challenge of designing IS's as meaning attribution systems in which people select certain resources out of the mass potentially available and get them processed by means of IT, to make them meaningful in order to support their purposeful actions.
\end{abstract}

Keywords: Organization Transformation, Systems Thinking, IS Context

\section{Introduction}

In the emerging knowledge economy (OECD, 1996), as the possibilities of the information revolution challenge traditional business logic, organization transformation has become one of the most popular subjects on business management and information systems (IS) design. Organizations are being compelled to question and redesign their entire existing operations in a way that uses new information technologies (IT) to serve their business better. According to Venkatraman (1994), there are five levels of IT-enabled organization transformation. The first level is the application of IT to address functional requirements of high-value business operations in order to cut cost and to save time. The second level is to systematically leverage IT throughout an enterprise, involving technical interconnectivity, and business process interdependence. The idea is to build an electronic infrastructure, which carries a common pool of data and information that is

Material published as part of this journal, either on-line or in print, is copyrighted by Informing Science. Permission to make digital or paper copy of part or all of these works for personal or classroom use is granted without fee provided that the copies are not made or distributed for profit or commercial advantage AND that copies 1) bear this notice in full and 2) give the full citation on the first page. It is permissible to abstract these works so long as credit is given. To copy in all other cases or to republish or to post on a server or to redistribute to lists requires specific permission from the publisher at Publisher@InformingScience.org captured once, and then flows automatically to the point of need in every affected process. The third level is to initiate an IT-enabled redesign of critical business processes, involving a fundamental rethinking of what work must be done, why, and by whom, in the context of what technology makes possible and with special emphasis on 
creating learning loops and enhancing knowledge sharing. The fourth level is to lead the development of technology-enhanced business networks, involving the redesign and concomitant re-distribution of business activities across different organizations. The fifth level is to redefine the business scope through technology, involving the fundamental re-organization of activities in an organization's value chain. Venkatraman refers to the first two levels as evolutionary, and the last three as revolutionary. Our literature review has indicated that there have been failures to fully exploit level two, and to move from level two to level three (Earl, 1993; Goodhue, Quillard, \& Rockart, 1988; Goodhue, Kirsch, Quillard \& Wybo, 1992; Lederer \& Sethi, 1988). Indeed, the failure to move from technical to business process interdependence is largely responsible for the failure to move out of the evolutionary phase into the revolutionary stage. Retrospectively, IT professionals have been largely driven by the technology of information, and not the interconnectivity of information with other domains of the organization, notably its business processes and knowledge workers. Meanwhile, the emerging knowledge economy has witnessed the organization's continuous move from a principle of automation to one of integrative processes. This is somewhat analogous to the principle of 'informating' advanced by (Zuboff, 1988). While automation involves the removal of the individual from a process, informating is a form of process abstraction and integration between the individual and a computer system. Namely, through information technology, an individual manipulates the inputs and outputs of several tasks, sees beyond his or her immediate work, and is able to perceive the entire process. Besides informating, 'knowledging' as a third form of process integration, has appeared. Savage (1990) refers to knowledging as an active and continual process of interrelating patterns. It is more than the accumulation of and access to information, because it looks at both the known (information) and the visionary (what could be). Knowledging involves both explicit (the known) and tacit (the vision) forms of knowledge. It depends on people for interpreting the known and for embodying the vision. It is focused on learning and is characterized by the content and process of knowledge creation, individual motivation, and the active involvement of the individual with his or her work. Consequently, an organization that is focused on knowledging, is more likely to anticipate a culture of engagement among its members. Each successive transformation, from automating to informating to knowledging, requires higher levels of process abstraction and a broad range of process integration. For knowledge interconnectivity to work, individuals in an organization will have to play different roles such as operational, tactical and strategic ones. And managers are becoming organizational architects. Their new roles increasingly include designing organizational structures, engineering processes, developing people, leveraging information technologies, facilitating learning and integrating the whole change efforts.

\section{Organizations: The Main Context for IS Work}

In their 1977 publication, The Management of Innovation, Tom Burns and G.M. Stalker, argued that the form of an organization should be dependent on the situation in which it is trying to operate. They proposed two polar ideal types of organizations respectively known as the mechanistic and the organic systems. The former "mechanistic" system carries such features as hierarchical differentiation, vertical communication, and centralized authority, and they are often viewed as appropriate to stable conditions. By contrast, the latter "organic" system is characterized by an emphasis on the holistic tasks of the organization, collegial relationships, decentralized authority and horizontal as well as vertical communication. Such systems are considered as often appropriate to conditions of change or uncertainty, such as those prevailing in today's knowledge economy. This perspective from Burns and Stalker, has given IS designers the necessary organizational context required for aligning the various organizational pieces (called domains or constructs) such as strategy, people, resources, structure, goals and process. An example of the alignment is that there must be some strategy to combine people and resources in a suitable way in a particular structure, to create some process in order to achieve some defined goals compatible 
with the organization. In the following section, we examine the two strands of thinking in IS work together with the concept of organization in order to understand better the idea of an information system, which is established with the intention of serving or supporting members of an organization and the organization itself in the everyday world.

\section{The Hard and Soft Strands of IS Work}

Dominating IS work today is a set of assumptions which sees organizations as goal seeking (Checkland \& Holwell, 1995; Zwass, 1992), a characteristic of the command and control mechanistic model. The prime organizational activity is then decision-making in pursuit of goals, objectives or some longer-term mission. Information required by the organization is then that which supports and services decision-making. It is not difficult to criticize this view of the world, and there is currently some growing recognition in IS that an alternative strand of thinking is also relevant. Namely, people feel that being a member of an organization is more like being part of a family than being the servant of a rational machine. For such people, social reality is constantly being constructed and reconstructed in a social process in which meanings are negotiated. For them, an organization does not exist as an independent entity but is part of sense making by a group of people engaged in dialogue, an essential characteristic of the organic model. This makes the idea of information, and information system much more problematical, since information is now obviously related in some profound way to meaning attribution and sense making. Equally, this view will not automatically embrace would-be-scientific methods of investigation and research, based on systematic data collection aimed at hypothesis testing. It will seek alternative processes of inquiry in such areas as interpretative action research (Anderton, 1991; Boland, 1986; Checkland, 1988; Galliers, 1992). The difference between these schools of thought in IS work could be captured in the words 'hard' (for the objective scientific view) and 'soft' (for the subjective interpretative view). In the IS context, the hard approach assumes that organizations are systems with information needs which IT can supply; the soft approach takes a process view of organizations and explores, using soft systems ideas (Checkland \& Scholes, 1999) to structure action research, the way in which people in organizations inter-subjectively attribute meaning to their world and hence form a view on what information is relevant.

\section{The Hard Functional Strand}

In fact, in the hard strand of IS work, the notions of organization are usually accepted without being questioned (Robey \& Zmud, 1992). Namely, the typical view expounded is that organizations, assumed to be social entities, seek to achieve goals, with managerial activity being seen as decision-making in pursuit of the declared goals (Jackson, 1987). Essentially, an organization is considered to comprise a group of people who together can seek to achieve objectives which would be beyond the reach of an individual, and that the entity, the organization, can be thought of as a system, usually 'a socio-technical system' whose managing comprises such activities as planning, organizing, staffing, coordinating, directing and controlling. This latter thought usually conveys the view that an organization's members will be working in several different functional parts connected together, and changing any one of these will have some affect on all the others. As a member of such a social unit, a manager is a problem solver, and the fundamental activity in problem solving is decision making, which is the process of identifying a problem, identifying alternative solutions, and choosing and implementing one of them (Zwass, 1992). Information systems have an important role in this; namely, they are there to support individual decision-making. In fact, it is the work of Herbert Simon (Boland, 1987; Simon, 1960) which has persuaded so many people to assume the nature of managing to be problem solving through decision making. In Simon's words (1960, p. 27), "problem solving proceeds by erecting goals, detecting differences between present situation and goal, finding in memory or by search tools or processes 
that are relevant to reducing differences of these particular kinds, and applying these tools or processes. Each problem generates sub-problems until we find a sub-problem we can solve. We proceed until, by successive solution of such sub-problems, we eventually achieve our overall goal - or give up."

\section{The Soft Interpretive Strand}

In the soft strand, nevertheless, an organization is seen at core as a social process, essentially a conversational process, in which the world is interpreted in a particular way which legitimates shared actions and establishes shared norms and standards. There is no single body of work, which underlies the soft (interpretive) approach to information systems, but the work of Sir Geoffrey Vickers (1965) provide quite an interesting reference. For Vickers, organizational managers set standards or norms rather than goals, and the focus on goals is replaced by one on managing relationships according to standards generated by previous history of the organization. Furthermore, the discussion and debate which leads to action is one in which those taking part make judgments about both 'what is the case' (Vickers' reality judgments) and about its evaluation as good or bad, satisfactory or unsatisfactory - what Vickers calls appreciative judgments. This places Vickers work firmly in the interpretive tradition, which sees social action as based upon personal and collective sense making. Interestingly, Vickers' idea is also at the core of the writings of Winograd and Flores (1986), whose much-noticed Understanding Computers and Cognition is written from the point of view that language as a medium does not simply reflect the world out there but constitutes it in the social process of interaction. This leads them to the view that organizations are constituted as networks of conversations in which commitments are generated. Information systems can support such conversations: "Computers are a tool for conducting the network of conversation (page 172)." Another author within the soft strand of IS thinking is Ciborra (1987). He argues that organizations should be seen as networks of communicative exchanges, and that computer-based information systems should be thought of as making such exchanges easier - the exchange support systems. He contrasts this idea with the more conventional view within IS work, when he writes: "Present-day IS designers either tend to a data view of organizations, or in the case of those most influenced by business needs, to a decision-making view. These two ways of looking at the problems of computerization are so widely accepted and have been so much taken for granted that they can be said to form the conventional wisdom of today. The origins of the former can be traced directly back to the EDP field, while the latter stem from the influential work of Herbert Simon."

\section{A Concept of Organization for IS}

In developing a richer concept of organization than that on which most IS work and most of its literature are based, the problem is to capture the tension between the rationality of collectively organizing to achieve declared goals and the ultimate recalcitrance of human beings as members of organizations (Checkland \& Holwell, 1998). The tension referred to is central in the writings of a pioneering sociologist, Ferdinand Tonnies. In seeking to understand the transition from agrarian to industrial society, Tonnies, in his major work Gemeinschaft und Gesellschaft (1887) (translated as Community and Association by Loomis (1955)) constructed models of two types of society or organizations. These were on the one hand the natural living community of the family (Gemeinschaft), the group which we find ourselves part of, and on the other, the formally created associations (Gesellschaft) which men and women join in some complicated contractual sense as when we choose to become employees of a company. This is the basis of a typology for analysis rather than a description of actual organizations. The interesting point is that actual organizations in the world, although artificially designed and created, also continue to have some of the natural characteristics of the family, thanks to the ultimate autonomy and unpredictability of hu- 
man beings: no Gesellschaft is ever simply a rational machine whose members willingly combine together totally to pursue organizational goals. In trying to build a picture of organization capable of better supporting IS work we first assume that the word 'organization' always refers to a social unit, or collectivity. It is a social collectivity concerned with some collective action, and there are associated social practices, which relate to this. Accordingly, to be a member of an organization is to have a contractual relationship with it, whether a legal contract of employment or a more complex psychological contract, or both. Members of an organization in a role structure are assumed to share an image of their organization in terms of its context, aims and objectives, its structures, processes and resources, and the measures of performance, which indicate whether or not the aims are being achieved. Within this framework, the members make their contribution to decision making in pursuit of objectives. Nonetheless, it is the readiness of people, members and non-members of the organization alike, which causes the organizational entity to exist. People talk and act as if there were a collective entity, which could behave like a conscious being, with the ability to decide to do things and then make them happen. Oftentimes, there are conceptualizations based on the interests and agendas of individuals, or sub-groups within the organizations as well as the overall declared, public, official account of the organization. The existence of these different interests and agendas means that the organization as a whole, the collectivity, has constantly to seek accommodations between conflicting interests upon which action can be based. It cannot simply assume consensus. And, following Vickers, the action is here expressed more richly as managing a changing set of relationships, rather than taking rational decisions to achieve goals.

\section{A Pragmatic Model of IS Support}

As an account of the context of IS work, we consider the orderly provision of information in organizations as one important aspect of organizational change. Accepting this is to assume that organizations can never be static but are always changing in response to changing circumstances, both internal and external. Wise people in organizations will try to ensure that problems are perceived, framed and tackled consciously; and a ubiquitous feature of such organizational problem-solving activity will be work to create orderly systems of information provision. In any case, the provision of information systems, even if done only in response to technological imperatives, will itself bring about organizational change. It is assumed that this organizational change activity will in principle be capable of being fed by four particular bodies of relevant knowledge, represented by four streams of thinking and activity: information systems, systems thinking, IT, and organizational theory. The IS stream is that concerned with fundamental idea of data, information and knowledge, also with methodology for IS planning and development and the managing of the information resource in organizations. The systems stream consists of the body of systems thinking, which emerged with general systems theory in the 1950s and is relevant to anything which may be thought of as a complex whole. The technology stream refers to the body of knowledge and work, which focuses on IT and its development. It is important because, although IT provides a possible means (a 'how') to achieving the end of a working system to provide information (a 'what'), this is a technology in which new ways of doing things technically, new 'hows', can change ideas about possible 'whats'. The fourth stream is concerned with understanding organizations, and organizational behavior. This is the context of IS work, work which can hardly be undertaken without taking as given some concept of what an organization is. In fact, any particular piece of work in IS may draw upon any or all of these areas. Obviously, we must describe how and with what an organization performs its IS work. Here the alignment context is often expressed in terms of the dynamics of the people-process-system issue. Namely, we need to design suitable information systems to help people with knowledge to perform the processes involved to produce results of value to the organization. In fact, Zuboff (1988) has written extensively on the interaction of people and information technology (IT), and the all-important shift in management 
thinking from automating to informating. In practice, automating typically refers to the use of IT during process change to substitute the deployment of humans. Automating serves to lower uncertainty and increase management control. Informating, in contrast, refers to the effect IT may have on the understanding and transparency of a process. Informating makes people more productive through their use of, and process integration with IT. It serves to increase the capacity of people to understand the entire value-adding business process. Thus, informating concerns itself with the connection people have with their specific tasks as well as the whole flow of work. Certainly, the notion of knowledge cannot be neglected. While informating concerns IT and task integration, the idea of knowledging (Savage, 1990) refers to individual and organizational learning, and is characterized by the process of knowledge creation and the active involvement of the individual with his or her work. Knowledging includes a dynamic interaction between the known (explicit) and the vision (tacit) forms of knowledge. In fact, each context from automating to informating to knowledging, may be thought of as a stage, a progression requiring additional alignment threads and trade-off. In particular, the trade-off between individualism and community may impact the movement from informating to knowledging. Individualism drives individual knowledge and rewards, and thus encourages informating, while a community emphasizes sharing and is more closely associated with knowledging, including the interaction of computers, people, lateral relations, business processes, and organizational learning (including knowledge creation). Thereby, in order to create a pragmatic model for IS support, each successive organizational transformation, from automating to informating to knowledging, requires higher levels of process abstraction and a broad range of process integration and alignment threads.

\section{The Challenge in Systems Thinking for IS Design}

The practice of systems thinking, according to Peter Checkland (1981, 1983, 1999), refers to a consciously organized process of thinking using systems ideas, which emerged as a generalization of ideas about organisms, and which were developed in the first half of the twentieth century, through the systems movement attributed to the Austrian Ludwig von Bertalanffy (1968). At the core of systems thinking is a concept, which clearly derives from our intuitive knowledge of organisms: the concept of a whole entity, which can adapt and survive, within limits, in a changing environment. This notion of the adaptive whole is the central image in systems thinking, and the systems movement can be regarded as the attempt to explore the usefulness of this particular concept in many different fields. Today, systems-thinking has emerged as a meta-discipline and as a meta-language which can be used in the study of many different fields (Checkland and Haynes1994), including natural systems (the study of the wholes created by nature in physical sciences), designed systems (the study of the wholes designed and made by human beings in engineering disciplines) as well as management systems (the study of human activities in social sciences). Not surprisingly the two areas of work, involving natural and designed wholes, are ones in which there is in general good mapping between the systems concepts and the observed real world. But, such mapping is much more problematic in the third broad area of application, that of human activities. In the 1960s, the main development of systems thinking within human activities was essentially systematic in character. Namely, it is confined to a small subset of situations in which objectives are undisputed, so that problems are only 'how to do it?' problems, not problems of 'what to do?' In the 1970s and 1980s, it was found that what usually made the situations problematic in applying systems thinking, was the inability to define objectives precisely, given the changing, multiple, ambiguous, and conflicting alternatives. The problems were at the level of 'what to do?' as well as 'how to do it?' The way out of this dilemma was to consider the real-world ubiquity of purpose in human activities and to treat a linked set of human activities that constitute a purposeful whole as a new system-type we now call the human activity system (HAS), the models of which could then be used as devices to structure questioning of the problem situation. This process, which later became known as the soft system methodology (SSM) 
(Checkland \& Scholes, 1999; Wilson 2001) is systemic in nature; it is a learning system, a system of enquiry, which happens to make use of models of human activity systems. The difference between the systemic thinking (how to do without what to do) and the systematic thinking (how to do with what to do), according to (Checkland, 1983), is now thought of as marking the difference between the soft systems thinking of the 1970s and 1980s and the hard systems thinking of the earlier approaches. The key difference between them is that the hard tradition assumes that systems exist in the world and can be engineered to achieve declared objectives. The soft tradition assumes that the world is problematic, always more complex than any of our accounts of it, but that the process of enquiry into the world can itself be engineered as a learning system, one in which soft systems thinkers have the option consciously to adopt the hard stance if necessary. It is this shift of systemicity, from assuming systems to exist in the world to assuming that the process of enquiry into the world can be organized as a learning system, which defines the two tracks of systems thinking today.

\section{Implications for Information Systems}

In the previous sections, we examined the context in which most work on IS is done - organizations - and discovered the idea of an organization to be more subtle than we usually bother to acknowledge; namely, the view that organizations are social units whose members collectively pursue declared objectives. Given this, the basic organizational process is seen as rational decision making in pursuit of the explicit aims. This simple notion apparently provides a clear definition of the role of an IS: it is to provide the information, which supports the decision- making at the various levels of an organization, say from the strategic to the operational. Meanwhile, it is understood that organizations can also be seen as cultural processes in which social reality is continually defined and re-defined in both the talk and action, which carries and expresses the multiple agendas of both organization members and significant non-members outside the organization. Against this background, we are now in a position to examine the concept of information, treating this as something needed in support of the purposeful action which goes on in organizations; needed, that is, if the action is to be defensible, well-informed, better than simply playing hunches or randomly thrashing about. Consequently, if information is interpreted as what we get when human being attribute meaning to data in a particular context, then an information system (IS), in the full sense, will be a meaning attribution system in which people select certain data out of the mass potentially available and get them processed to make them meaningful in a particular context in order to support people who are engaged in purposeful action (Checkland \& Holwell, 1995). Systems-thinking offers an important insight into this role of information systems, which are not created for their own sake. IS's serve or support people engaged in what for them is meaningful action. The implications of systems thinking, especially soft system thinking are as follows: we can provide a way of conceptualizing the social processes in which, in a particular organizational context, a particular group of people can conceptualize their world and hence the purposeful action they wish to undertake. That provides the basis for ascertaining what information support is needed by those who undertake that action. Only then does it become appropriate to ask how modern information technology (IT) can help to provide that support, and to provide it. This is to see information systems as systems, which attribute meaning to selected data in which someone has an interest, by processing it - usually by means of IT - in a way which makes it meaningful to users of the system. It should also be of interest to note that meaning attribution can never be completely institutionalized, which will continue to make IS a rich and fascinating area of work. 


\section{Implications for Information Systems Development}

It is understood that the variety of real-world problems concerning IS support for knowledge work, is enormous; however, it is useful to see them as lying within a spectrum which extends from 'hard' to 'soft'. There are a number of ways in which 'hard' and 'soft' can be defined, but the definition often cited is in terms of the degree of agreement about what the problem is among the particular population of individuals to whom the problem is of concern. At the hard end of the problem spectrum, the methodology applicable essentially consists of the following stages, with stages 2 and 3 being plausibly iterative: 1) define the problem; 2) assemble the appropriate techniques; 3) use techniques to derive possible solutions; 4) select most suitable solution; and 5) implement the solution. This structured approach to conceiving IS support for knowledge work, requires judgment in terms of a set of guidelines, which stimulate the intellectual process of analysis. At the soft end of the problem spectrum, the first of the above stages 'define the problem' is itself problematic since it usually depends on who defines it. Given that there will usually be a number of people concerned with or involved in 'the problem' there will be a number of legitimate definitions. Thus, the methodology applicable here, has to start by defining, not a problem but a situation that is problematic. Its stages of development could be characterized as follows with plausible iterations in stages 3,4 and 5: 1) define the situation that is problematic; 2) express the situation with different sets of concerns; 3 ) select concepts that may be relevant; 4) assemble concepts into an intellectual structure; 5) use this structure to explore the situation; 6) define changes to the situation as the problems to be tackled; and 7) implement the change processes. In this rhetoric of IS work, we just mention a more elaborate account of the thinking and methodology which underpins the work of designing IS support through the SSM framework for action research in which desirable change and organizational learning are often considered as the aims. Consequently, the problems of IS support should never be thought of as something to be defined once and for all and then implemented. Rather, a strategy for IS support needs to be thought of as the current position in a process which is ongoing. The most important feature for an organization which is to remain viable is not that it has a set of meanings which it attributes to its world, and hence an IS strategy and a set of information systems, but rather that it has a constantly-attended-to process, integrated into organizational activity, by which it adjusts to its changing world. Indeed, finding ways of institutionalizing that constant adaptation is something few organizations do well. However, from the IS architects' point of view, while conceiving the necessary IS support to serve the specific organizational requirements, the fundamental ideas could be summarized as follows. Always start from a careful account of the purposeful activity served by the system. From that, work out what informational support is required by people carrying out the activity. Treat the creation of that support as a collaborative effort between technical experts and those who truly understand the purposeful action served. Meanwhile, ensure that both system creation and system use are treated as opportunities for continuous learning.

\section{Conclusion}

To be sure, information technology (IT) is helpful, perhaps indispensable, in the modern organization. But, information systems design meets a great challenge in facilitating a group's commitment to a concept, sharing emotions tied to tacit experience, or embodying the knowledge related to a certain task. The human skills that drive knowledge creation have much more to do with relationships and community building than databases. Investments in information technology alone cannot induce a smooth organization transformation. Information systems are concerned not only with the development of new information technologies, but also with questions such as: how they can best be applied, how they should be managed, and what their wider implications are. Our focus in this paper has been on information systems and their possible creation, mainly in an organizational context. Although it is accepted that technological development may well create new 
possibilities which may lead to a re-thinking of organizational forms and processes, the focus on IS rather than IT is a conscious decision based on a particular view: information systems exist to serve, help or support people taking action in the real world, and it is a fundamental proposition that in order to conceptualize, and so create, a system which serves, it is first necessary to conceptualize that which is served, since the way the latter is thought of will dictate what would be necessary to serve or support it. The starting point of this work, then, is a re-thinking of what is entailed in providing informational support to purposeful action in the real world of organizations. From that, a clearer view emerges of the nature of information systems and IS as a field of study. It is not, nevertheless, primarily a theoretical work; rather, it is based on the belief that thinking about the world and having experiences in it cannot be easily separated. The experiences are interpreted by (but also serve to create) ideas and concepts which in turn make sense of (new) experiences.

\section{References}

Anderton, R. H. (1991). Information and systems. Journal of Applied Systems Analysis, 18, 57-60.

Boland, R. J. (1986). Phenomenology: A preferred approach to research on information systems. In Langefors, Verrijn-Stuart \& Bracchi (Eds.), Trends in information systems. North Holland, Amsterdam.

Boland, R. J. (1987). The in-formation of information systems. In Boland \& Hirschheim (Eds.). Critical issues in information systems research. Chichester: John Wiley and Sons.

Burns, T. \& Stalker, G. M. (1977). The management of innovation ( $2^{\text {nd }}$ ed.). London: Tavistock.

Checkland, P. (1981). Systems thinking, systems practice. Chichester: Wiley.

Checkland, P. (1983). Information systems and systems thinking: Time to unite? International Journal of Information Management, 8, 239-248.

Checkland, P. (1999). Systems thinking. In W.L. Currie, \& B. Galliers (Eds.), Rethinking management information systems. Oxford University Press.

Checkland, P. \& Holwell, S. (1995). Information systems: What's the big idea? Systemist, 17 (1), pp. 7-13.

Checkland, P. \& Holwell, S. (1998). Information, systems, and information systems: Making sense of the field. Chicheser: John Wiley and Sons.

Checkland, P. \& Scholes, J. (1999). Soft systems methodology in action. Chichester: Wiley.

Ciborra, C. U. (1987). Research agenda for a transaction costs approach to information systems. In Boland \& Hirschheim (Eds), Critical issues in information systems research. Chichester: John Wiley and Sons.

Earl, M. J. (1993). Experiences in strategic information systems planning. MIS Quarterly, March, pp. 1-24.

Galliers, R. (1992). Choosing information systems research approaches. In R. Galliers (Ed), Information Systems research: Issues, methodology and practical guidelines. Oxford: Blackwell.

Goodhue, D. L., Quillard, J. A., \& Rockart, J. F. (1988). Managing the data resource: A contingency perspective. MIS Quarterly, 12 (3), September.

Goodhue, D. L., Kirsch, L. J., Quillard, J. A., \& Wybo, M. D. (1992). Strategic data planning: Lessons from the field. MIS Quarterly, March.

Jackson, M. C. (1987). Systems strategies for information management in organizations which are not machines. International Journal of Information Management, 7, 187-195.

Lederer, A. L., \& Sethi, V. (1988). The implementation of strategic information systems planning methodologies. MIS Quarterly, 12 (3), September, pp. 445-461. 
Loomis, C. P. (1955). Translation of Tonnies' Gemeinschaft and Gesellschaft (1887). London: Routledge \& Kegan Paul.

OECD (1996). The Knowledge-Based Economy, Organization for Economic Co-operation and Development, OCDE/GD(96)102, Paris.

Robey, D. \& Zmud, R. (1992). Research on the organization of end-user computing: Theoretical perspectives from organization science. Information Technology and People, 6 (1), 11-27.

Savage, C. M. (1990). Fifth generation management: Integrating enterprises through human networking. Digital Press.

Senge, P. (1990). The fifth discipline: The art and practice of the learning organization. London, U.K: Currency Doubleday.

Simon, H. A. (1960). The new science of management decision. , New York: Harper and Row.

Spek, R. van der, \& Spijkervet, A. (1997). Knowledge management: Dealing intelligently with knowledge. In: J. Liebowitz \& L.C. Wilcox (Eds.), Knowledge management and its integrative elements (pp.31-59). New York, USA: CRC Press.

Stopford, J., M. (2001). Organizational learning as guided responses to market signals. In M. Dierkes, A.B. Antal, et al. (Eds.), Handbook of organizational learning and knowledge (pp. 264-281). Oxford University Press.

Venkatraman, N. (1994). IT-enabled business transformation: From automation to business scope redefinition. Sloan Management Review, Winter.

Von Bertalanffy, L. (1968). General system theory. New York: Braziller.

Vickers, G. (1965). The art of judgment. London: Chapman and Hall.

Wilson, B. (2001). Soft systems methodology: Conceptual model building and its contribution. New York: John Wiley \& Sons.

Winograd, T. \& Flores, F. (1986). Understanding computers and cognition. Reading, MA: Addison-Wesley.

Zuboff, S. (1988). In the age of the smart machine: The future of work and power. New York: Basic Books.

Zwass, V. (1992). Management information systems. Dubuque, IA: Wm. C. Brown.

\section{Biography}

Kam Hou Vat is currently a lecturer in the Department of Computer and Information Science, under the Faculty of Science and Technology, at the University of Macau, Macau SAR, China. His current research interests include learner-centered design with constructivism in Software Engineering, architected applications developments for Internet software, information systems for learning organization, information technology for knowledge synthesis, and collaborative technologies in electronic organizations. 